\title{
AUDIT SISTEM INFORMASI
}

\author{
Marina ainy \\ 175100045 \\ Fakultas Komputer \\ marinaainy.students@umitra.ac.id
}

\begin{abstract}
Pengertian Audit Sistem Informasi Menurut Para Ahli

Alvin A. Arens dan James K. Loebbecke

Pengertian audit sistem informasi menurut Alvin A. Arens dan James K. Loebbecke adalah auditing is the accumolation and evaluation of evidence about information to determite and report on the degree of correspondence between the information and establishe criteria. Examining ought to be finished by a skillfull autonomous individual.
\end{abstract}

Ron Weber (1999)

Pengertian audit sistem informasi menurut Ron Weber adalah System information auditing is the process of collecting and evaluating evidence to determite whether a computer system safeguards assets, maintains data integrity, allows organizational goals to the achived effectively and uses resources efficiently. Artinya Audit sistem informasi adalah proses mengumpulkan dan mengavaluasi fakta untuk memutuskan apakah sistem komputer yang merupakan aset perusahaan terlindungi, integritas data terpelihara, sesuai dengan tujuan organisasi untuk mencapai efektifitas dan efisiensi dalam penggunaan sumber daya.

Kata Kunci : audit sistem informasi 


\begin{tabular}{|c|c|}
\hline $\begin{array}{l}\text { A. PENDAHULUAN } \\
\text { B. } \mathrm{P} \\
\mathrm{e}\end{array}$ & $\begin{array}{l}\text { disebut juga EDP Audit } \\
\text { (Electronc Data Processing }\end{array}$ \\
\hline $\mathrm{n}$ & Audit) / Computer audit \\
\hline $\begin{array}{l}\mathrm{g} \\
\mathrm{e}\end{array}$ & merupakan suatu proses \\
\hline $\mathrm{r}$ & dikumpulkannya data dan \\
\hline $\begin{array}{l}\mathrm{t} \\
\mathrm{i}\end{array}$ & dievakuasinya butki untuk \\
\hline $\mathrm{a}$ & menetapkan apakah suatu \\
\hline $\mathrm{n}$ & sistem aplikasi komputerisasi \\
\hline A & sudah diterapkan \\
\hline $\begin{array}{l}\mathrm{u} \\
\mathrm{d}\end{array}$ & menerapkan \\
\hline $\mathrm{i}$ & pengendalian, internal yang \\
\hline $\mathrm{t}$ & sudah sepadan, seluruh aktiva \\
\hline $\mathrm{S}$ & dilindungi dengan baik atau \\
\hline $\mathrm{i}$ & disalahgunakan dan juga \\
\hline $\mathrm{t}$ & terjamin integrita \\
\hline $\begin{array}{l}\mathrm{e} \\
\mathrm{m}\end{array}$ & $\begin{array}{l}\text { keandalan dan juga efektifitas } \\
\text { dan efisiensi penyelenggaraan }\end{array}$ \\
\hline $\begin{array}{l}\mathrm{I} \\
\mathrm{n}\end{array}$ & informasi berbasis komputer. \\
\hline$f$ & E. \\
\hline $\mathrm{O}$ & G. $\mathrm{Pe}$ \\
\hline $\begin{array}{l}\mathrm{r} \\
\mathrm{m}\end{array}$ & ng \\
\hline $\mathrm{a}$ & ert \\
\hline $\mathrm{s}$ & $\mathrm{Au}$ \\
\hline C. ${ }^{\mathrm{i}}$ & dit \\
\hline D. Audit sistem informasi atau & Sis \\
\hline Information System Audit & $\begin{array}{l}\text { te } \\
\mathrm{m}\end{array}$ \\
\hline
\end{tabular}




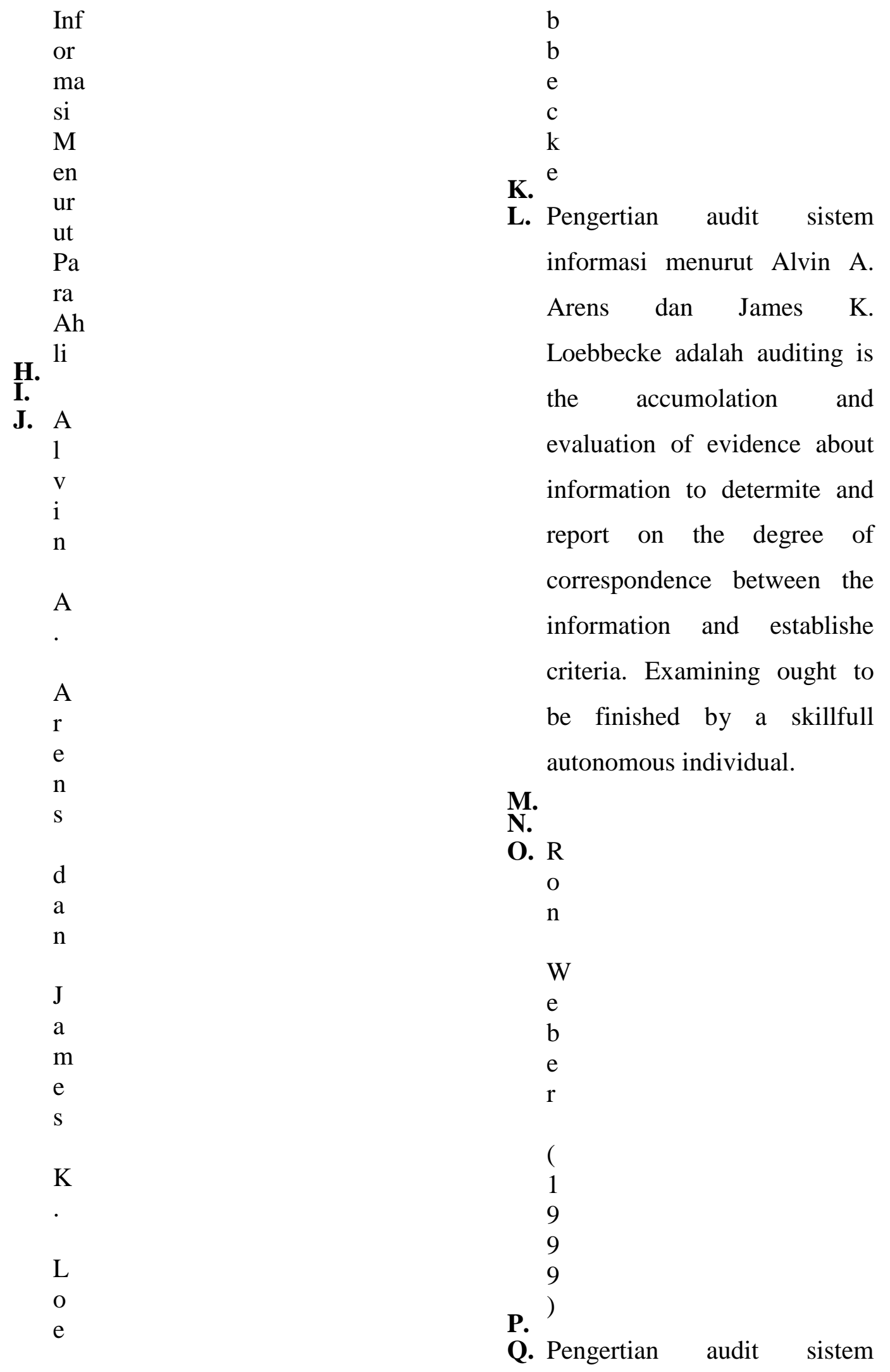




$$
\begin{aligned}
& \text { informasi menurut Ron } \\
& \text { Weber adalah System } \\
& \text { information auditing is the } \\
& \text { process of collecting and } \\
& \text { evaluating evidence to } \\
& \text { determite whether a computer } \\
& \text { system safeguards assets, } \\
& \text { maintains data integrity, } \\
& \text { allows organizational goals to } \\
& \text { the achived effectively and } \\
& \text { uses resources efficiently. } \\
& \text { Artinya Audit sistem } \\
& \text { informasi adalah proses } \\
& \text { mengumpulkan dan } \\
& \text { mengavaluasi fakta untuk } \\
& \text { memutuskan apakah sistem } \\
& \text { komputer yang merupakan } \\
& \text { aset perusahaan terlindungi, } \\
& \text { integritas data terpelihara, } \\
& \text { sesuai dengan tujuan } \\
& \text { organisasi untuk mencapai } \\
& \text { efektifitas dan efisiensi dalam } \\
& \text { penggunaan sumber daya. }
\end{aligned}
$$

\section{R. PEMBAHASAN / STUDI KASUS}

Proses pengumpulan data menggunakan metode Audit Sistem Informasi dengan menggunakan Kuisioner sebagai wadah pengumpulan data
Dan ini merupakan perhitungan saya dengan menggunakan Microsoft Excel

S. ID SECURITY

QWTD4452377-ASP-5244166

\section{T. KESIMPULAN}

Berdasarkan Hasil kegiatan

Dalam Pengumpulan data saya menggunakan metode Pembuatan Kuisioner di SMK N 1 Gading Rejo, Kecamatan Gading Rejo, Kabupaten Pringsewu difokuskan pada tanggapan siswa maupun tenaga pendidikan khususnya bidang tata usaha dalam meningkatkan pelayanan yang diberikan semoga untuk kedepannya kinerja dari bidang tata usaha dapat berjalan dengan baik lagi

\section{U. DISKUSI}

Sebagai sarana pengolahan informasi dan pelayanan di SMK N 1 Gading Rejo, harus selalu melakukan yang terbaik dalam hal pelayanan . agar semoga kedepannya lulusan dari SMK N 1 Gading Rejo 
memiliki Mutu yang lebih baik lag

\section{REFERENCE}

[1] O. M. Febriani and A. S. Putra, "Sistem Informasi Monitoring Inventori Barang Pada Balai Riset Standardisasi Industri Bandar Lampung," J. Inform., vol. 13, no. 1, pp. 90-98, 2014.

[2] A. S. Putra, "Paperplain: Execution Fundamental Create Application With Borland Delphi 7.0 University Of Mitra Indonesia," 2018.

[3] A. S. Putra, "2018 Artikel Struktur Data, Audit Dan Jaringan Komputer," 2018.

[4] A. S. Putra, "ALIAS MANAGER USED IN DATABASE DESKTOP STUDI CASE DB DEMOS."

[5] A. S. Putra, "COMPREHENSIVE SET OF PROFESSIONAL FOR DISTRIBUTE COMPUTING."

[6] A. S. Putra, "DATA ORIENTED RECOGNITION IN BORLAND DELPHI 7.0."

[7] A. S. Putra, "EMBARCADERO DELPHI XE 2 IN GPUPOWERED FIREMONKEY APPLICATION."

[8] A. S. Putra, "HAK ATAS KEKAYAAN INTELEKTUAL DALAM DUNIA TEKNOLOGY BERBASIS REVOLUSI INDUSTRI 4.0."

[9] A. S. Putra, "IMPLEMENTASI PERATURAN PERUNDANGAN UU. NO 31 TAHUN 2000 TENTANG
DESAIN INDUSTRI BERBASIS INFORMATION TECHNOLOGY."

$\begin{array}{lr}\text { A. S. } & \text { Putra, } \\ \text { "IMPLEMENTATION } & \text { OF }\end{array}$ PARADOX DBASE."

[11] A. S. Putra, "IMPLEMENTATION OF TRADE SECRET CASE STUDY SAMSUNG MOBILE PHONE."

[12] A. S. Putra, "IMPLEMENTATION

PATENT FOR APPLICATION WEB BASED CASE STUDI WWW. PUBLIKLAMPUNG. COM."

[13] A. S. Putra, "IMPLEMENTATION SYSTEM FIRST TO INVENT IN DIGITALLY INDUSTRY."

[14] A. S. Putra, "MANUAL REPORT \& INTEGRATED DEVELOPMENT

ENVIRONMENT BORLAND DELPHI 7.0."

[15] A. S. Putra, "PATENT AS RELEVAN SUPPORT RESEARCH."

[16] A. S. Putra, "PATENT FOR RESEARCH STUDY CASE OF APPLE. Inc."

[17] A. S. Putra, "PATENT PROTECTION FOR APPLICATION INVENT."

[18] A. S. Putra, "QUICK REPORT IN PROPERTY PROGRAMMING."

[19] A. S. Putra, "REVIEW CIRCUIT LAYOUT COMPONENT

REQUIREMENT ON ASUS NOTEBOOK."

[20] A. S. Putra, "REVIEW TRADEMARK PATENT FOR 
INDUSTRIAL TECHNOLOGY BASED 4.0."

[21] A. S. Putra, "TOOLBAR COMPONENT PALLETTE IN OBJECT ORIENTED PROGRAMMING."

[22] A. S. Putra, "WORKING DIRECTORY SET FOR PARADOX 7."

[23] A. S. Putra, "ZQUERY CONNECTION

IMPLEMENTED

PROGRAMMING

STUDI

CASE PT. BANK BCA Tbk."

[24] A. S. Putra, D. R. Aryanti, and I. Hartati, "Metode SAW (Simple Additive Weighting) sebagai Sistem Pendukung Keputusan Guru Berprestasi (Studi Kasus: SMK Global Surya)," in Prosiding Seminar Nasional Darmajaya, 2018, vol. 1, no. 1, pp. 85-97.

[25] A. S. Putra and O. M. Febriani, "Knowledge Management Online Application in PDAM Lampung Province," in Prosiding International conference on Information Technology and Business (ICITB), 2018, pp. 181-187.

[26] A. S. Putra, O. M. Febriani, and B. Bachry, "Implementasi Genetic Fuzzy System Untuk Mengidentifikasi Hasil Curian Kendaraan Bermotor Di Polda Lampung," SIMADA (Jurnal Sist. Inf. dan Manaj. Basis Data), vol. 1, no. 1, pp. 21-30, 2018.

[27] A. S. Putra, H. Sukri, and K. Zuhri, "Sistem Monitoring Realtime Jaringan Irigasi Desa (JIDES) Dengan Konsep Jaringan Sensor Nirkabel,"
IJEIS (Indonesian J. Electron. Instrum. Syst., vol. 8, no. 2, pp. 221-232.

[28] D. P. Sari, O. M. Febriani, and A. S. Putra, "Perancangan Sistem Informasi SDM Berprestasi pada SD Global Surya," in Prosiding Seminar Nasional Darmajaya, 2018, vol. 1, no. 1, pp. 289-294. 